\title{
Medical students' interests on rural practices
}

\author{
Khairinnisa Maizal Gazali ${ }^{1}$, Rizma Adlia Syakurah ${ }^{2}$, Mariatul Fadilah \\ ${ }^{1}$ Undergraduate Program, Medical Faculty, Sriwijaya University, Indonesia \\ ${ }^{2,3}$ Department of Public Health and Community Medicine, Medical Faculty, Sriwijaya University, Indonesia
}

\begin{abstract}
Article Info
Article history:

Received Mar 20, 2019

Revised Apr 30, 2019

Accepted May 14, 2019

\section{Keywords:}

Career preference

Medical students

Rural area

Undergraduate

ABSTRACT

Misdistribution of physicians is still an issue, especially physicians' lack of interest to work in rural area. Finding characteristics from medical students that show interest to work in rural areas is important to craft effective policy to enforce young physicians to work in rural areas. This study was quantitative analytics. Participants rated the influence of 19 factors that affect their interest towards working in rural area using translated and validated questionnaire, distributed online to all medical students from 20 medical faculties in Sumatra. Out of 1,124 respondents, 748 (66.5\%) subjects interested to work in rural area. Determinants which influence medical students' interest towards working in rural area are past experience of visiting rural area $(\mathrm{p}<0.001)$, careers opportunity $(\mathrm{p}<0.001)$, family's socioeconomic status $(\mathrm{p}=0.001)$, proximity to family $(\mathrm{p}=0.001)$, rural area's facilities $(\mathrm{p}=0.002)$, culture of rural community $(\mathrm{p}=0.005)$, students' lifestyle $(\mathrm{p}=0.005)$, rural curriculum $(\mathrm{p}=0.007)$, proximity to spouse $(\mathrm{p}=0.031)$ and location of university $(\mathrm{p}=0.049)$. Past experience of visiting rural area (OR 2.281, $\mathrm{p}<0.001)$ is the most determining factor to influence students' interest towards working in rural area. Medical students mostly interested to work in rural area. Past experience of visiting rural area was the most influential factor for medical students' interest on rural practices.
\end{abstract}

Copyright (C) 2019 Institute of Advanced Engineering and Science. All rights reserved.

\section{Corresponding Author:}

Rizma Adlia Syakurah,

Department of Public Health and Community Medicine, Medical Faculty,

Sriwijaya University, Dr. Mohammad Ali St. RSMH Km. 3,5 Palembang, Indonesia.

Email: rizma.syakurah@gmail.com

\section{INTRODUCTION}

Health development problem of health workers misdistribution is still common to be encountered in many countries worldwide. Many rural areas are in the shortage of health workers due to this misdistribution, especially in low-income and middle-income countries [1]. Healthcare workforce which is distributed unequally between urban and rural areas leads to poorer health quality for people living in rural areas [2-3]. As an illustration, on calculation, the number of doctors in Indonesia is sufficient for national needs. However, most of them are concentrated in urban areas. For example, in Nias, Indonesia, there are only 31 general practitioners and 8 specialists among 133,388 populations spread over Nias [4]. Meanwhile, WHO recommended the ratio of doctors per population by 10: 10,000 [5].

Botswana and Malaysia are also encountering similar problems [6-7]. Malaysian residents who live in the suburbs such as Sabah have difficulties in health care services due to the minimum and difficult access to health facilities [7]. Rural jobs are highly unattractive for practicing health workers [8-10]. Health workers misdistribution problem is associated with the lack of interest in young doctors to work in rural areas [11]. A study in India showed about one out of five medical students showing career interest in rural locations after graduation [12].

A person's interest can be attributed to various factors. According to previous studies done based on Green behavioral theory, there were three groups of factors that determine the interest of medical students to 
work in rural areas, namely: predisposing factors including student background, lifestyle, hobbies, and social motives [13], enabling factors including facilities, culture in rural areas, geographic conditions, financial reasons, career opportunities [14], academic opportunities [15], and university (location, curriculum), and the reinforcing factors including policies made by schools, government regulations, the influence of spouses or families [14].

\section{RESEARCH METHOD}

This study was approved by the ethical committee of the Medical Faculty, Sriwijaya University (No. 364/kepkrsmhfkunsri/2016). This research was conducted with quantitative analytical research method, from September to October 2016. The instrument used in this study was translated and validated questionnaire distributed via online to all medical students from 20 medical faculties in Sumatra, Indonesia. The expected number of samples was as many as 400 people. The dependent variable in this study was the interest of students to work in rural areas and the independent variables were the factors that affected medical students' interest to work in rural areas. Descriptive statistics and normality test was performed, followed by multiple linear regression to model the relationship between dependent variable and independent variables. Potential confounders is controlled by using multivariate logistic regression analysis by analyzing the association of all variables together. Statistically significant results were defined as $\mathrm{p}<0.05$. The statistic analysis was done using IBM SPSS Statistics Base 22.0.

\section{RESULTS AND DISCUSSIONS}

In this study there were 1.124 respondents matched the inclusion criteria. The analysis was done by univariate, bivariate and multivariate. The study aimed to determine the determinants of medical students' interest to work in rural areas.

\subsection{Distribution of medical students' interest to work in rural areas}

There were $748(66.5 \%)$ of students showing interest of working in rural areas as shown in Table 1. Out of 1124 respondents, there were 943 of respondents had the experience of visiting rural areas, and $68.9 \%$ of them had the interest of working in rural areas. Respondents with no past experience of visiting rural areas were as many as 181 and $54.1 \%$ of them were interested to work in rural areas. The percentage of students' preference of working in rural areas was higher in those with past experience of visiting rural areas.

Table 1. Characteristics of medical students' interest to work in rural areas

\begin{tabular}{ccc}
\hline $\begin{array}{c}\text { Medical students' interest } \\
\text { to work in rural areas }\end{array}$ & $\mathrm{N}$ & $\%$ \\
\hline Interested & 748 & 66.5 \\
Uninterested & 376 & 33.5 \\
Total & 1,124 & 100 \\
\hline
\end{tabular}

\subsection{Determinants of medical students' interest to work in rural areas}

Determinants which influenced medical students' interest of working in rural areas were past experience of visiting rural areas $(\mathrm{p}<0.001)$, career opportunities $(\mathrm{p}<0.001)$, family economic status $(\mathrm{p}=0.001)$, proximity of location to family $(\mathrm{p}=0.001)$, rural area's facilities $(\mathrm{p}=0.002)$, rural community culture $(\mathrm{p}=0.005)$, students' lifestyle $(\mathrm{p}=0.005)$, curriculum about rural area $(\mathrm{p}=0.007)$, proximity of location to spouse $(\mathrm{p}=0.031)$, and university location $(\mathrm{p}=0.049)$. As can be seen in Table 2 , past experience of visiting rural area was the most dominant factor in influencing student interest to work in rural areas with the highest odd ratio of 2.281 .

Table 2. Determinants of medical students' interest to work in rural areas

\begin{tabular}{ccc}
\hline Variables & OR $(95 \%$ CI $)$ & $P$ \\
\hline Past experience of visiting rural area & $2.281(1.689-3.082)$ & $<0.001$ \\
Career opportunity & $2.157(1.425-3.265)$ & $<0.001$ \\
Family economic status & $0.567(0.403-0.797)$ & 0.001 \\
Proximity of location to family & $0.487(0.313-0.756)$ & 0.001 \\
Rural area's facilities & $0.531(0.353-0.799)$ & 0.002 \\
Rural community culture & $1.709(1.179-2.478)$ & 0.005 \\
Students' lifestlye & $0.616(0.441-0.861)$ & 0.005 \\
Curriculum about rural area & $1.600(1.134-2.257)$ & 0.007 \\
Proximity of location to spouse & $0.689(0.491-0.967)$ & 0.031 \\
University location & $0.704(0.497-0.999)$ & 0.049 \\
\hline Significant (p<0.05); OR, Odd Ratio; CI, Confidence Interval &
\end{tabular}




\subsection{Determination coefficient test $(\mathbf{R} 2)$}

The calculation result of $\mathrm{R} 2$ value in regression analysis obtained the coefficient of determination adjusted R2 of 0.106 (Cox Snell R square) and 0.147 (Nagelkerke R square) as shown in Table 3 . This suggested that the studied variables had accounted for $10.6 \%$ or $14.7 \%$ in determining medical students' interest to work in rural areas.

Table 3. R square on logistic regression

\begin{tabular}{cc}
\hline Cox \& Snell R square & Nagelkerke R square \\
\hline 0.106 & 0.147 \\
\hline
\end{tabular}

\subsection{Discussion}

Based on the results in this study, there were $66.5 \%$ of medical students showing interest of working in rural areas as can be seen in Table 1. This was consistent with study done in Ghana which stated that more than half of medical students had the desire to work in rural areas, as much as $57.4 \%$ [16]. The result of this study was inversely proportional to another studies done in Indonesia, also in range of Asia and Africa, which showed that medical students' preference to have career in rural areas was only $8.7 \%$ [14] and $18 \%$ [13] respectively. The disparity might be due to differences in perspective of rural conditions in each individual affected by the conditions of each regions.

In the analysis of the determinants of medical students' interest to work in rural areas, showed that past experience of visiting rural area, career opportunity, family economic status, proximity of location to family, rural area's facilities, rural community culture, students' lifestyle, curriculum about rural area, proximity of location to spouse and university location were empirically proven to be influential in determining the interest of students to work in rural areas.

Past experience of visiting rural area was the most influential and important factor in determining students' interest to work in rural areas (OR 2.281, 95\% CI 1.689-3.082, p<0.001). Visiting rural areas could raise student awareness of health needs and also encouraged urban-oriented students to consider themselves working in rural areas [14]. University curriculum about rural areas was also indirectly connected to the interest of students to work in rural areas [17]. Training in rural areas with a community-based curriculum and exposure to the community also motivated medical students to work in rural areas. Students who had spent at least two years in rural areas had high inclination to return back to rural areas after graduation [18]. Students with rural background or enrolled in medical schools located in rural areas also had tendencies to choose rural areas as their future career location [17, 19-22]. But this alone is not enough to ensure a return to rural areas [23-24].

The background of family with low economic status could also attract students to work in rural areas. Students coming from families with low economic status had more sense of caring to help others [16]. Thus, the background of students coming from families with low economic status could be used as priority of freshman admission in medical schools. Medical schools also may have criteria to select students with a rural background, experience and education. This inclusion of underserved communities is a potential solution for the misdistribution, because this will motivate medical students to serve in rural areas after graduation [24-27]. Students with families and spouse living in rural areas also had tendencies to choose rural areas as career location [14, 28]. Medical students also assumed that cultures of rural areas could also be in consideration in choosing rural areas as career location. While lack of infrastructure and facilities in rural areas demotivated medical students to work there [1, 29-30]. Far more advanced facilities in urban areas caused the medical students to be more interested to work in urban areas [14].

Career opportunities in rural areas also affected students' interest to rural practices [14]. Considered monetary compensation also enticed medical student to work in rural areas [28]. Willingness of working in certain areas is also influenced by the students' norms [31]. General practitioner especially in rural areas, is still the least preferred career prospect, with personal interest and social factors as main determinants. Career choices should be early introduced to students so they can start exploring and determine the right choices for it [32]. All parties including academic institutions and policymakers should consider this when planning attraction and retention strategies to decentralize doctors distribution from urban to rural areas [33].

\section{CONCLUSION}

Determinants of interest of medical students' to work in rural areas were past experience of visiting rural area, career opportunity, family economic status, proximity of location to family, rural area's facilities, 
rural community culture, students' lifestyle, curriculum about rural area, proximity of location to spouse and university location. Past experience of visiting rural area was the most determining factor in influencing students' interest on rural practices.

\section{ACKNOWLEDGEMENTS}

The authors would like to deliver gratitude to Sriwijaya University for making this study possible and all parties that supported this study.

\section{REFERENCES}

[1] Budhathoki SS, Zwanikken PAC, Pokharel PK, Scherpbier AJ. Factors influencing medical students' motivation to practise in rural areas in low-income and middle-income countries: a systematic review. BMJ Open 2017; 7(2): e013501. (https://www.ncbi.nlm.nih.gov/pubmed/28232465)

[2] Sousa A, Dal Poz MR, Boschi-Pinto C. Reducing inequities in neonatal mortality through adequate supply of health workers: evidence from Newborn Health in Brazil. PLoS ONE 2013; 8:e74772. (http://journals.plos.org/plosone/article?id=10.1371/journal.pone.0074772)

[3] Srinivasan CS, Zanello G, Shankar B. Rural-urban disparities in child nutrition in Bangladesh and Nepal. BMC Pub Health 2013; 13:581. (https://bmcpublichealth.biomedcentral.com/articles/10.1186/1471-2458-13-581)

[4] Central Bureau of Statistics Republic of Indonesia. The Number of Specialist Doctors, General Physicians, and Dentist in Health Care Facilities in Nias Regency. (in Bahasa: Banyaknya Dokter Spesialis, Dokter Umum, dan Dokter Gigi di Sarana Pelayanan Kesehatan di Kabupaten Nias 2013, 2013. (https://niasbaratkab.bps.go.id/linkTabelStatis/view/id/32)

[5] Ministry of Health Republic of Indonesia. "Strategic Plan of the Ministry of Health for 2015-2019" (in Bahasa: "Rencana Strategis Kementrian Kesehatan Tahun 2015-2019”). Jakarta: Ministry of Health Republic of Indonesia, 2015. (www.depkes.go.id/resources/download/info-publik/Renstra-2015.pdf)

[6] Nkomazana O, Mash R, Shaibu S, Phaladze N. Stakeholders' perceptions on shortage of healthcare workers in primary healthcare in Botswana: focus group discussions. PLoS One 2015;10(8):e0135846.(http://journals.plos.org/plosone/article?id=10.1371/journal.pone.0135846)

[7] Ali O, Noor MTM. Rural Medical Education in Sabah, Malaysia. Bangkok, WONCA (World Organization of Family Doctors) Working Party on Rural Practice, 2014; p.1

[8] Huicho L, Canseco FD, Lema C, Miranda JJ, Lescano AG. Incentives to attract and retain the health workforce in rural areas of Peru: a qualitative study. Cad Saude Publica 2012; 28:729-39. (https://www.ncbi.nlm.nih.gov/pubmed/22488318)

[9] Huicho L, Miranda JJ, Diez-Canseco F, Lema C, Lescano AG, Lagarde M, et al. Job preferences of nurses and midwives for taking up a rural job in Peru: a discrete choice experiment. PLoS One 2012; 7 , e50315. (http://journals.plos.org/plosone/article?id=10.1371/journal.pone.0050315)

[10] Miranda JJ, Diez-Canseco F, Lema C, Lescano AG, Lagarde M, Blaauw D, et al. Stated preferences of doctors for choosing a job in rural areas of Peru: a discrete choice experiment. PLoS One 2012;7, e50567. (http://journals.plos.org/plosone/article?id=10.1371/journal.pone.0050567)

[11] Department of Health Republic of Indonesia. "Distribution of Doctors Regarding the Interest of Doctors to Work in Remote Areas" (in Bahasa: "Distribusi Dokter Berkaitan dengan Minat Dokter untuk Bekerja di Daerah Terpencil”). Jakarta, Depkes RI, 2013. (http://www.depkes.go.id/article/view/13100014/distribusi-dokterberkaitan-dengan--minat-dokter-untuk-bekerja-di-daerah-terpencil.html\#sthash.NthIRFsp.dpuf)

[12] Diwan V, Minj C, Chhari $\mathrm{N}$ et al. Indian medical students in public and private sector medical schools: are motivations and career aspirations different? — studies from Madhya Pradesh, India. BMC Med Educ 2013; 13:127. (http://link.springer.com/article/10.1186/1472-6920-13-127)

[13] Silvestri DM, Blevins M, Afzal AR, Andrews B, Derbew M, Kaur S, et al. Medical and nursing student's intention to work abroad or in rural areas: a cross-sectional survey in Asia and Africa. Bull World Health Organ, 2014. (https://www.ncbi.nlm.nih.gov/pubmed/25378729)

[14] Syahmar I, Putera I, Istatik Y, Furqon MA, Findyartini A. Indonesian medical students' preferences associated with the intention toward rural practice. Rural Remote Health. 2015; Oct-Dec; 15(4):3526. (www.rrh.org.au/publishedarticles/article_print_3526.pdf)

[15] King KR, Purcell RA, Quinn SJ, Schoo AM, Walters LK. Supports for medical students during rural clinical placements: factors associated with intention to practise in rural locations. Rural Remote Health 2016; 16: 3791. (www.rrh.org.au/publishedarticles/article_print_3791.pdf)

[16] Kotha S, Johnson JC, Galea S, Agyei-Baffour P, Nakua E, Asabir K, Kwansah J, Gyakobo M, Dzodzomenyo M, Kruk ME. Lifecourse factors and likelihood of rural practice and emigration: a survey of Ghanaian medical students. Rural Remote Health 2012; 12: 1898. (www.rrh.org.au/publishedarticles/article_print_1898.pdf)

[17] Rural Health West. Critical Success Factors Recruiting and Retaining Health Professional to Primary Health Care in Rural and Remote Locations. Australia, The University of Western Australia, 2013. (http://www.ruralhealthwest.com.au/docs/default-source/marketing/publications/rhw_uwa_cucrh-contemporaryreview-of-the-literature-f-lr.pdf?sfvrsn=2) 
[18] Kapanda GE, Muiruri C, Kulanga AT, Tarimo CN, Lisasi E, Mimano L, Mteta K, Bartlett JA. Enhancing future acceptance of rural placement in Tanzania through peripheral hospital rotations for medical students. BMC Med Educ 2016; 16: 51. (https://www.ncbi.nlm.nih.gov/pubmed/26861915)

[19] Yeganeh-Arani E, Chandratilake M, Muula AS. Factors affecting career preferences of medical students at the College of Medicine, Malawi. S Afr Med J 2012; 102(4):249-251. (https://www.ncbi.nlm.nih.gov/pubmed/22464509)

[20] Farmer J, Kenny A, McKinstry C et al. A scoping review of the association between rural medical education and rural practice location. Hum Resour Health 2015; 13:27. (https://human-resourceshealth.biomedcentral.com/articles/10.1186/s12960-015-0017-3)

[21] Ross AJ. Working in rural areas-the experiences of Umthombo Youth Development Foundation graduates. Afr J Prim Health Care Fam Med 2014; 6:E1-7. (https://www.ncbi.nlm.nih.gov/pmc/articles/PMC4565023/)

[22] Crampton PES, McLachlan JC, Illing JC. A systematic literature review of undergraduate clinical placements in underserved areas. Med Educ 2013; 47:969-78. (https://www.ncbi.nlm.nih.gov/pubmed/24016167)

[23] Rockers PC, Jaskiewicz W, Wurts L, et al. Preferences for working in rural clinics among trainee health professionals in Uganda: a discrete choice experiment. BMC Health Serv Re 2012; 12:212. (https://www.ncbi.nlm.nih.gov/pubmed/22824497)

[24] Clark TR, Freedman SB, Croft AJ, et al. Medical graduates becoming rural doctors: rural background versus extended rural placement. Med J Aust 2013; 199(11):779-782. (https://www.ncbi.nlm.nih.gov/pubmed/24329657)

[25] Larkins S, Michielsen K, Iputo J et al. Impact of selection strategies on representation of underserved populations and intention to practise: international findings. Med Educ 2015; 49:60-72. (https://www.ncbi.nlm.nih.gov/pubmed/25545574)

[26] Jones MP, Eley D, Lampe L et al. Role of personality in medical students' initial intention to become rural doctors. Aust J Rural Health 2013; 21:80-9. (https://www.ncbi.nlm.nih.gov/pubmed/23586569)

[27] Jones MP, Bushnell JA, Humphreys JS. Are rural placements positively associated with rural intentions in medical graduates? Med Educ 2014; 48:405-16. (https://www.ncbi.nlm.nih.gov/pubmed/24606624)

[28] Arscott-Mills T, Kebaabetswe P, Tawana G, Mbuka DO, Makgabana-Dintwa O, Sebina K, Kebaeste M, Mokgatlhe L, Nkomazana O. Rural exposure during medical education and student preference for future practice location - a case of Botswana. Afr J Prim Health Care Fam Med 2016; 8:1. (http://www.phcfm.org/index.php/phcfm/article/view/1039/html)

[29] Borracci RA, Arribalzaga EB, Couto JL, Dvorkin M, Ahuad Guerrero RA, Fernandez C, Ferreira LN, Cerezo L. Factors affecting willingness to practice medicine in underserved areas: a survey of Argentine medical students. Rural Remote Health 2015 Oct-Dec; 15(4):3485. (https://www.ncbi.nlm.nih.gov/pubmed/26625931)

[30] Nallala S, Swain S, Das Sanju,Kasam I,and Pati S. Why medical students do not like to join rural health service? An exploratory study in India. $J$ Family Community Med 2015; 22: 2. p111-117. (https://www.ncbi.nlm.nih.gov/pmc/articles/PMC4415126/)

[31] Horváth F, Terebessy A, Pongor V, Balázs P. Ethical norms of medical school students and the workforce migration. $N$ Med 2015; 1:s. 25-28. (www.newmedicine.pl/wp-content/uploads/2015/04/newmed_2015_025028.pdf)

[32] Syakurah RA, Prabandari YS, Widyandana, Kumara A. Career choices, determinants, and need for medical career introduction among medical students. Int J Res Med Sci 2017;5:1998-2002. (www.msjonline.org/index.php/ijrms/article/view/2943)

[33] Huicho L, Molina C, Diez-Canseco F, Lema C, Miranda JJ, Huayanay-Espinoza CA, Lescano AG. Factors behind job preferences of Peruvian medical, nursing and midwifery students: a qualitative study focused on rural deployment. Hum Resour Health 2015; 13:90. (https://www.ncbi.n lm.nih.gov/pmc/articles/PMC4667493/) 